\title{
INFLUENCIA DE DIFERENTES CAVALOS E DA ÉPOCA DE COLHEITA NO TEOR DE VITAMINA C NA LARANJA NATAL
}

\author{
J. T. A. GURGEL (1) \\ J. LEME, Jr. (2) \\ E. MALAVOLTA (3) \\ H. MONTENEGRO (4)
}

\begin{abstract}
INDICE

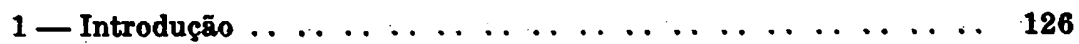

2 - Material e métodos $\ldots \ldots \ldots \ldots \ldots \ldots \ldots \ldots \ldots \ldots \ldots \ldots 126$

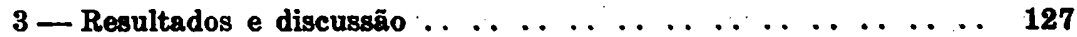

4-Resumo e conclusões . . . . . . . . . . . . . . . . . . 128

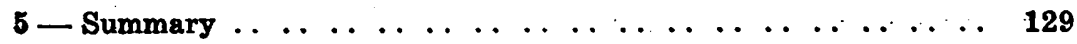

6 - Literatura citada . . . . . . . . . . . . . . . . . . . 130
\end{abstract}

(1) Secção de Genética, E. S. A. "Luiz de Queiroz", U. S. P.

(2) Seção de Tecnologia Agrícola, E. S. A. "Luiz de Queiroz", U. S. P.

(3) Seção de Química Agrícola, E. S. A. "Luiz de Queiroz", U. S. P.

(4) Secção de Horticultura, E. S. A. "Luiz de Queiroz", U. S. P. 


\section{1 - INTRODUÇÃO}

Existem na literatura científica sôbre a enxertia numerosos casos onde se constatou efetivamente uma interação entre cavalo e cavaleiro.

Estando em estudos a determinação do teor de vitamina C da coleção de citrus da Secção de Horticultura da "Escola Superior de Agricultura "Luiz de Queiroz" e havendo para as variedades mais importantes vários exemplares oriundos todos da mesma matriz e enxertados em diferentes cavalos, antevimos a possibilidade de conjugar êsses dois fatores bastante interessantes num só experimento: grau de maturação e influência do porta-enxerto sôbre o enxerto.

Para a execução dêste experimento colaboraram quatro Secções Técnicas da "Luiz de Queiroz", quais sejam as de Horticultura, Genética, Química Agrícola e Tecnologica.

\section{2 - MATERIAL E MÉTODOS}

Para êste experimento foi escolhida a laranja Natal ( $\mathrm{C} i$ trus sinensis) enxertada sôbre três cavalos, tais como laranja Serra d'Agua (.C sinensis) limão francès (C. reticulata) e limão rugoso (C. limon); para cada combinação foram tomadas 3 plantas, uma ao lado da outra. Destas colheram-se aproximadamente 30 frutos com intervalo de 3 semanas. A amostra média do suco era tomada da seguinte forma: escolhiam-se 10 frutos que estavam aparentemente no mesmo grau de maturação, e com o auxílio de espremedor doméstico extraia-se o caldo; numa alíquota determinava-se a acidez por titulação com $\mathrm{NaOH} 0,1 \mathrm{~N}$ e noutra achava-se a porcentagem de sólidos totais, com um refratometro de campo da marca Zeiss (Jena).

A seguir, calculava-se a relação sólidos totais/acidez e escolhiam-se as 5 amostras com as relações aproximadamente iguais e as mais altas possíveis; nessas amostras era dosada a vitamina $\mathrm{C}$ de acordo com a técnica de LEME, Jr. e MALAVOLTA (1950). Como veremos posteriormente, esse tipo de amostragem mostrou-se ser muito eficiente. 


\section{3 - RESULTADOS E DISCUSSÃO}

\subsection{Análise estatística da variação do experimento}

$\mathrm{O}$ experimento constou de determinação da riqueza em vitamina C de laranja Natal sôbre 3 diferentes cavalos, como limão Francês, laranja Serra d'Água e limão rugoso, e ainda em 4 épocas; para cada cavaleiro foram tomadas 3 árvores e em cada análise foram feitas 5 repetições. Portanto, o número total de variáveis será de 3 cavaleiros $\times 3$ cavalos $\times 4$ épocas $\times 5$ determinações igual a 180 (quadro 1).

A marcha da decomposição da variação total seguiu a de um esquema fatorial, com duas séries de fatores : 3 cavalos (2nf) em 4 épocas (3nf), ficando assim para a interação 3 × 2 igual a $6 \mathrm{nf}$.

O erro residual I corresponde a variação entre as 5 determinações em todas as 36 plantas ( 3 cavaleiros $\times 3$ cavalos $\times 4$ épocas); êle mede assim a exatidão química das análises (36 plantas x 5 repetições) e tem portanto $144 \mathrm{nf}(180-36)$, com um valor de $\pm 1,58 \mathrm{mg} / 100 \mathrm{~g}$. Calculando-se o coeficiente de variação desse êrro residual I achamos um valor de $3,4 \%$ que é perfeitamente aceitável para as análises químicas (última parte do quadro 2).

A segunda componente do quadro 2, ou seja o êrro residual II, corresponde essencialmente à variação das plantas nos cavalos-épocas e desde que as determinações do conteudo em ácido ascórbico foram feitas em cada uma das 4 épocas e para cada um das 3 cavalos, temos $2 \times 12$ igual a 24 nf. Esta componente é 1,5 vêzes maior que o êrro residual I, com significância no nível de $1 \%$ de probabilidade.

Assim, notamos que essa variação possa ser devida a variabilidade dos proprios indivíduos ou a manchas do terreno. Todavia, esta componente, apezar da sua significância estatística pode ser considerada como sem importância real, pois calculando-se o seu êrro em porcento, obtemos um valor de apenas $5,1 \%$, aliás bem baixo. Finalmente, as 3 componentes que correspondem a primeira parte do quadro 1 são altamente significantes quando comparadas com o êrro residual do experimento e diferem estatisticamente entre si muito pouco. 


\subsection{Análise estatística das médias}

Conforme vemos no quadro 3 , houve variação bastante acentuada entre as médias de vitamina $C$ por cavalo e ainda dentro das épocas; para melhor precisarmos a significação dessas diferenças, podemos calcular um teste de t. Empregando o êrro da diferença entre as médias dos cavalos-épocas, de $\pm 0,58$, calculado de 15 observaçöes ( 3 plantas x 5 épocas), sendo assim a diferença mínima significativa, no nível de $1 \%$ de probabilidade, de $\mathrm{t} x \sigma$ diferença ou 1,73 .

Assim, podemos constatar que a laranja Natal, enxertada sôbre 3 diferentes cavalos, deu o seguinte resultado: a) Serra d'Agua. Este cavalo deu em todas as épocas a maior riqueza em vitamina C, e ainda mais, o teor do ácido ascórbico decresce suavemente da primeira a quarta época; b) Limão francês. Aqui notamos que êste cavalo manteve constante e num nível relativamente alto nas duas primeiras épocas a taxa de vitamina $C$, seguido por uma forte queda, não sòmente da segunda para terceira, como também da terceira para a quarta época; c) Limão rugoso. Este cavalo mostrou na primeira época um teor relativamente baixo do ácido ascóbico, aumentou e manteve-se constante na segunda e terceira época, e finalmente na quarta época voltou ao nivel da primeira.

De acôrdo com os resultados obtidos, podemos dizer que os 3 cavalos influenciaram diferentemente o conteúdo de vitamina $C$ do cavaleiro; notou-se ainda que num mesmo cavalo pode variar bastante o teor do ácido ascórbico nos vários estágios de maturação do fruto, ou por outras, que a época de colheita tem importância na riqueza em vitamina C da laranja Natal.

\section{4 - RESUMO E CONCLUSOES}

Estudou-se a variação no teor da vitamina $\mathrm{C}$ da laranja Natal em função do cavalo e da época de colheita. As determinações foram feitas no suco de frutos apresentando pràticamente a mesma relação sólidos totais/acidez, usando-se como critério de amostragem apenas os valores mais altos da citada relação. Os resultados podem ser resumidos assim: 
4.1. Há influência significativa do cavalo sôbre o teor de vitamina $C$ do cavaleiro; tal influência toma dois aspectos interessantes : o primeiro é o teor de ácido ascórbico em si que difere de acôrdo com o cavalo considerado; o segundo é o modo de variação na quantidade de vitamina $\mathbf{C}$ em função do cavalo, isto é, a maior ou menor flutuação quando se considera as diversas colheitas : enquanto em um (Serra d'Água) o teor decresce suavemente, em outros (limão francês) o nível permanece mais ou menos constante para depois cair bruscamente; finalmente no caso do limão rugoso o teor de ácido ascórbico sobe para depois voltar ao nivel primitivo.

4.2. O teor de ácido ascórbico, independentemente do cavalo, varia apreciàvelmente em função da época de colheita; êste fator deve, portanto, ser considerado quando se faz a amostragem para a determinação da vitamina $C$ na laranja.

\section{5 - SUMMARY}

This paper deals with the variation of the ascorbic acid content in Natal orange as related to the type of rootstock and to the picking time. The determinations were carried out in the juice of fruits which had practically the same ratio total solids/acidity being selected only the highest values of such quotient. The results can be summaryzed as follows :

5.1. The rootstock has a significant influence on the vitamin $\mathrm{C}$ content of the scion; this influence shows two interesting aspects : first, the ascorbic acid contet itself varies as a function of the rootstock; among the three rootstocks studied the highest values were obtained on scion growing on Serra d'água orange; the lowest values were found in "limão rugoso" and "limão francês" was intermediate; the second point to be emphasyzed is the manner of variation of the ascorbic acid content in the different rootstocks : in the case of Serra d'água, 
the content decreases slowly whereas in "limão francês" the level remains nearly constant and suddenly falls down; finally in the case of "limão rugoso" the amount of ascorbic acid increases significantly to return to the primitive level.

5.2. The amount of ascorbic acid, not considering the rootstock influence, varies strongly. as a function of harvesting time; for this reason the present factor must be borne in mind when sampling for the determination of ascorbic acid in orange is concerned.

\section{6 - LITERATURA CITADA}

LEME Jr., J. e E. MALAVOLTA. 1950. Determinação fotométrica do ácido ascórbico. An. E. S. A. "Luiz de Queiroz", U. S. P. 7: 115-129. 


\section{QUADRO 1}

Taxas de vitamina $\mathrm{C}$ expressa em $\mathrm{mg}$ por $100 \mathrm{~g}$ de caldo fresco, para combinação de laranja Natal sôbre três cavalos.

Para cada época foram feitas cinco repetições

\begin{tabular}{|c|c|c|c|c|c|}
\hline \multirow{2}{*}{ CAVALO } & \multirow{2}{*}{$\mathbf{P E}$} & \multicolumn{4}{|c|}{ Vitamina $C-m g / 100 g$} \\
\hline & & $18 / 4$ & $7 / 5$ & $25 / 5$ & $12 / 6$ \\
\hline \multirow[t]{3}{*}{ Laranja Serra d'Água| } & 1 & $\begin{array}{l}58,8 \\
58,8 \\
58,3 \\
59,6 \\
60,2 \\
\end{array}$ & $\begin{array}{l}57,5 \\
56,0 \\
56,7 \\
57,5 \\
56,8 \\
\end{array}$ & $\begin{array}{l}49,3 \\
45,4 \\
45,4 \\
49,3 \\
47,5\end{array}$ & $\begin{array}{l}38,2 \\
38,2 \\
43,3 \\
39,2 \\
39,2 \\
\end{array}$ \\
\hline & 2 & $\begin{array}{l}59,0 \\
59,0 \\
64,1 \\
64,1 \\
64,0 \\
\end{array}$ & $\begin{array}{l}56,7 \\
56,7 \\
56,8 \\
56,7 \\
56,7\end{array}$ & $\begin{array}{l}47,0 \\
49,3 \\
45,4 \\
45,0 \\
47,2 \\
\end{array}$ & $\begin{array}{l}38,2 \\
39,2 \\
40,8 \\
43,0 \\
38,0 \\
\end{array}$ \\
\hline & 3 & $\begin{array}{l}59,2 \\
59,0 \\
62,9 \\
58,1 \\
64,1 \\
\end{array}$ & $\begin{array}{l}56,5 \\
57,0 \\
58,7 \\
57,5 \\
57,5 \\
\end{array}$ & $\begin{array}{l}45,4 \\
45,4 \\
49,2 \\
47,2 \\
45,3 \\
\end{array}$ & $\begin{array}{l}43,0 \\
43,0 \\
43,0 \\
43,0 \\
43,0 \\
\end{array}$ \\
\hline \multirow[t]{3}{*}{ Limão Francês } & 1 & $\begin{array}{l}53,6 \\
54,1 \\
54,9 \\
53,6 \\
53,0 \\
\end{array}$ & $\begin{array}{l}53,6 \\
54,5 \\
53,6 \\
54,0 \\
54,3 \\
\end{array}$ & $\begin{array}{l}43,4 \\
40,8 \\
38,3 \\
41,7 \\
42,9 \\
\end{array}$ & $\begin{array}{l}22,7 \\
25,3 \\
25,3 \\
23.1 \\
22,7 \\
\end{array}$ \\
\hline & 2 & $\begin{array}{l}54,1 \\
53,6 \\
53,6 \\
52,8 \\
52,9 \\
\end{array}$ & $\begin{array}{l}54,1 \\
52,7 \\
63,9 \\
54,0 \\
53,6 \\
\end{array}$ & $\begin{array}{l}43,4 \\
43,4 \\
43,4 \\
40,8 \\
40,8 \\
\end{array}$ & $\begin{array}{l}27,9 \\
22,7 \\
22,7 \\
25,3 \\
22,7 \\
\end{array}$ \\
\hline & 3 & $\begin{array}{l}56,7 \\
53,6 \\
54,1 \\
53,6 \\
53,9 \\
\end{array}$ & $\begin{array}{l}54,2 \\
54,0 \\
53,5 \\
53,6 \\
54,2 \\
\end{array}$ & $\begin{array}{l}39,3 \\
39,3 \\
43,4 \\
43,4 \\
40,8 \\
\end{array}$ & $\begin{array}{l}25,3 \\
20,1 \\
22,9 \\
23,2 \\
22,7 \\
\end{array}$ \\
\hline \multirow[t]{3}{*}{ Limão Rugoso } & 1 & $\begin{array}{l}39,3 \\
37,4 \\
36,2\end{array}$ & $\begin{array}{l}51,0 \\
51,1 \\
50,8 \\
\end{array}$ & $\begin{array}{l}40,5 \\
45,9 \\
43,2 \\
\end{array}$ & $\begin{array}{l}35,6 \\
33,5 \\
33,5 \\
\end{array}$ \\
\hline & 2 & $\begin{array}{l}34,7 \\
38,7 \\
38,7 \\
38.7 \\
33,8 \\
\end{array}$ & $\begin{array}{l}49,7 \\
50,0 \\
49,9 \\
48,3 \\
48,0 \\
\end{array}$ & $\begin{array}{r}40,8 \\
40,8 \\
43,3 \\
43,2 \\
40,8 \\
\end{array}$ & $\begin{array}{l}38,2 \\
33,5 \\
33,5 \\
33,5 \\
\mathbf{3 5 , 0} \\
\end{array}$ \\
\hline & 3 & $\begin{array}{l}33,8 \\
34,1 \\
33,8 \\
32,9 \\
33,1\end{array}$ & $\begin{array}{l}50,1 \\
49,8 \\
50,1 \\
49,0 \\
48,9\end{array}$ & $\begin{array}{l}41,7 \\
40,8 \\
43,3 \\
43,3 \\
40,8 \\
\end{array}$ & $\begin{array}{l}35,6 \\
37,5 \\
35,0 \\
33,1 \\
33,1\end{array}$ \\
\hline
\end{tabular}


QUADRO 2

\begin{tabular}{|c|c|c|c|c|}
\hline COMPONENTES & $\begin{array}{c}\text { Grau de } \\
\text { liberdado }\end{array}$ & $\left|\begin{array}{cc}\text { Erro padrão } \\
\mathbf{m g} / \mathbf{1 0 0 g}\end{array}\right|$ & $\begin{array}{l}\text { Toste de } \\
\text { teta ( }\end{array}$ & $\begin{array}{c}\text { Teste de teta ( } \\
\text { int.) }\end{array}$ \\
\hline $\begin{array}{l}\text { Entre cavalos } \\
\text { Entre épocas } \\
\text { Interação (cavalo x época) }\end{array}$ & $\begin{array}{l}2 \\
3 \\
6\end{array}$ & $\begin{array}{l} \pm 42,52 \\
\pm 60,32 \\
\pm 26,08 \\
\end{array}$ & $\begin{array}{l}27,10 * * * \\
38,18 * * * \\
16,51 * * *\end{array}$ & $\begin{array}{r}1,64 \\
2,31 \\
--- \\
\end{array}$ \\
\hline Resíduo II (entre plantas) & 24 & $\pm 2,31$ & $1,46 * *$ & c. $\mathrm{v} .=5,1 \%$ \\
\hline Resíduo I (entre determin.) & 144 & $\pm 1,58$ & - & c. $\mathrm{v} .=3,4 \%$ \\
\hline
\end{tabular}

QUADRO 3

Conteúdo de vitamina $\mathrm{C}$ de laranja Natal colhida em diferentes épocas e sôbre três cavalos, expressa em mg por $100 \mathrm{~g}$ de suco fresco

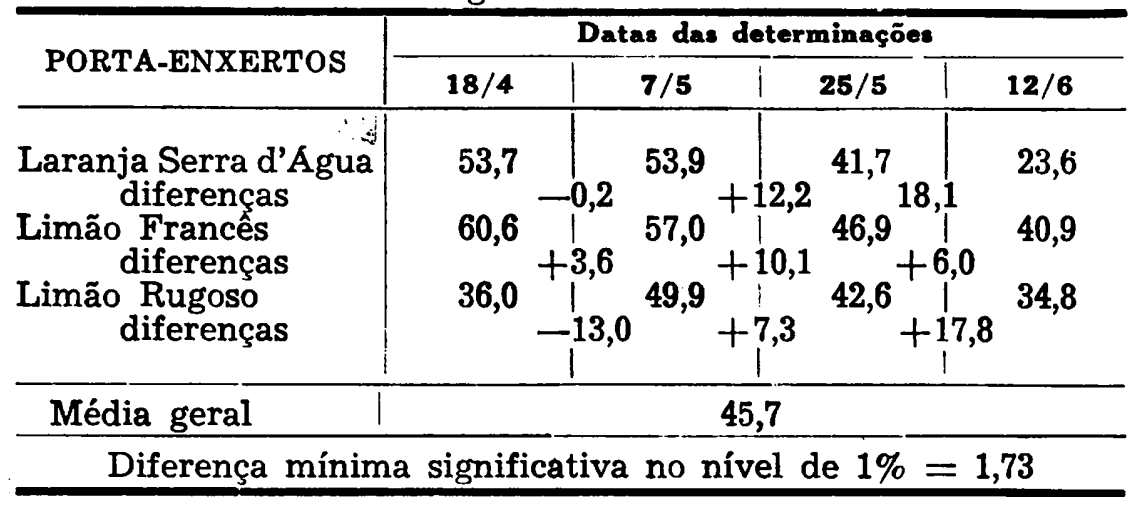

